Tropical Journal of Pharmaceutical Research, June 2004; 3 (1): 285-290

(C) Pharmacotherapy Group,

Faculty of Pharmacy, University of Benin,

Benin City, Nigeria.

All rights reserved.

Available online at http://www.tjpr.freehosting.net

Opinion Article

\title{
Effects of interacting variables on the release properties of chloroquine and aminophylline suppositories
}

\section{Michael A Odeniyi and Kolawole T Jaiyeoba ${ }^{\Phi}$}

Department of Pharmaceutics and Industrial Pharmacy, Faculty of Pharmacy, University of Ibadan, Ibadan, Nigeria

\begin{abstract}
Purpose: The individual and interaction effects of formulation variables on the release of suppositories were investigated using a $2^{3}$ factorial experimental design. The variables studied were nature of base (B), type of drug (D), and presence of surfactant (S).

Method: Suppositories were formulated with theobroma oil and Witepsol H15 as bases at 'low' and 'high' levels respectively. Chloroquine and aminophylline, both water-soluble drugs, were incorporated as active constituents at 'low' and 'high' levels respectively while Tween 80 was incorporated as surfactant in some of the formulations. Disintegration time and time taken for $50 \%$ of the drug to dissolve were used as assessment parameters.

Results: The inclusion of surfactant in the suppository formulation proved to be the most significant variable in the formulation. The ranking for the individual coefficient values for the formulations was $S>>B>D$ for disintegration time $D T$ and $S>>>D>B$ for the dissolution parameter $t_{50}$. While the ranking for the interaction effects was $B-D>B-S>S-D$ on $D T$ and on $t_{50} S-D>B-S>B-D$.

Conclusion: The results suggest that in formulating water-soluble drugs such as chloroquine and aminophylline as suppositories in a hydrophobic base, the presence of a surfactant is the most influential variable.
\end{abstract}

Keywords: Suppositories, chloroquine, aminophylline, surfactant, interacting variables.

$\boldsymbol{\Phi}_{\text {To whom correspondence should be addressed: E-mail: jaiyeobakt@yahoo.co.uk }}$ 


\section{Introduction}

The processes of release and absorption of drugs from suppositories are complex. The process of absorption has been described as involving three stages ${ }^{1}$ : (i) destruction (i.e. disintegration) of the suppository, (ii) transfer of the drug from the excipients to the rectal medium i.e. drug release, and (iii) absorption of the drug via the rectal mucosa. Release and subsequent absorption depend to a great extent on the viscosity of the suppository mass and on the mechanism of release from fatty bases. It has been found reasonable ${ }^{1}$ to use a fat-like base for watersoluble drugs. Furthermore, the diffusion rate of drug suspended in a fat base of both low hydroxyl number and viscosity is increased ${ }^{2}$.

In the formulation of different drugs as suppositories, there is the need to determine the optimum formulation factors which depend on the drug candidate itself, suppository base and the presence of an adjuvant. It is known that the composition of suppository bases is an important factor in the release process. In addition, drug absorption can be modulated by the incorporation of absorption enhancers. The inclusion of these enhancers have been widely reported ${ }^{3,4}$ and the main consideration for their selection is safety, efficacy and compatibility with other formulation ingredients ${ }^{3}$.

In the present work, we have carried out a simple quantitative assessment of how base type, drug type and presence or absence of surfactant affect the release characteristics of chloroquine and aminophylline suppositories using a three-way analysis of variance to determine the effects and extent of interactions between the three variables at two levels on the properties of suppositories. This type of analysis has been employed by various workers ${ }^{5,6,7}$ and has been found to be relevant to formulation and assessment of pharmaceutical systems.
Chloroquine is slightly acidic in solution, while aminophylline is slightly alkaline. Both are freely water-soluble and the aim of the work is to obtain the best formulation for the drugs that would serve as a template for the suppository formulation of such watersoluble drugs.

\section{Materials and Methods}

\section{Materials}

These were chloroquine phospate powder B.P (Bayer, Germany), aminophylline powder B.P., Witepsol H15 (Penn Pharmaceuticals Ltd. U.K), theobroma oil B.P. (Analar Laboratory Reagents, U.K), and tween 80 (Raymond Lamb Chemicals, U.K).

\section{Preparation of chloroquine and aminophylline suppositories}

Chloroquine and aminophylline suppositories were prepared by fusion method following an earlier described method ${ }^{8,9}$ using theobroma oil and Witepsol $\mathrm{H}-15$ as the suppository bases. Prior to incorporation, the drugs were passed through a $100 \mu \mathrm{m}$ mesh sieve. Each batch of suppositories was prepared in metal moulds with six cavities. Using the displacement value calculation, $100 \mathrm{mg}$ of each drug with and without absorption enhancer (the polyoxyethylenesorbitan fatty ester), Tween 80 , at a concentration of $0.5 \% \mathrm{w} / \mathrm{v}$ were incorporated into the suppositories. The suppositories were kept at room temperature for $24 \mathrm{hr}$ after removal from the moulds to allow for uniform solidification and crystal transformation.

\section{Analysis of samples}

For the analysis of chloroquine samples, calibration curve data were generated using solutions of the phosphate salt in $\mathrm{pH} 7.2$ buffer solution ${ }^{8}$ in the concentration range of $5 \times 10^{-4}$ to $5 \times 10^{-3} \% \mathrm{w} / \mathrm{v}$ and absorbance was measured at $343 \mathrm{~nm}$ using UV/visible spectrophotometer (Jenway 6305, 


\section{Odeniyi \& Jaiyeoba, 2004}

RealLabware Unit 33, Watford Herts, WD1 8SP, UK).

Calibration curve data for aminophylline was also generated using solutions of the drug in the $\mathrm{pH} 7.2$ buffer solution ${ }^{10}$ in the concentration range of $5 \times 10^{-4}$ to $5 \times 10^{-}$ ${ }^{3} \% \mathrm{w} / \mathrm{v}$ and absorbance was measured at $270 \mathrm{~nm}$ on UV spectrophotometer.

The mean drug content of each suppository was determined and found not to be less than $98 \%$.

\section{Data Analysis}

Three variables - nature of base (B), type of drug (D) and concentration of surfactant (S), were employed at a 'high' level (denoted by the subscript $H$ ) and a 'low' level (subscript L) in a $2^{3}$, i.e. 8 , factorial experimental design $^{11}$. Using the above nomenclature, the eight combinations between the variables were: $B_{L} D_{L} S_{L}, \quad B_{L} D_{H} S_{L}, B_{L} D_{H} S_{H}, B_{L} D_{L} S_{H}$, $B_{H} D_{L} S_{L}, B_{H} D_{H} S_{L}, B_{H} D_{H} S_{H}, B_{H} D_{L} S_{H}$.

$\mathrm{B}_{\mathrm{L}}=$ nature of base (theobroma oil)

$\mathrm{B}_{\mathrm{H}}=$ nature of base (Witepsol $\mathrm{H}$ 15)

$D_{L}=$ type of drug (chloroquine diphosphate)

$D_{H}=$ type of drug (aminophylline)

$\mathrm{S}_{\mathrm{L}}=$ nil surfactant $(0 \%$ Tween 80$)$

$\mathrm{S}_{\mathrm{H}}=$ presence of surfactant $(0.5 \%$ Tween 80$)$

The combinations were grouped into appropriate sets to enable the assessment of each variable on the value of disintegration time and dissolution time, and also to determine whether the variables were interacting or acting independently of each other. For example, the effect of increasing $B$ from the 'low' level to its 'high' level on disintegration and dissolution times was determined by summing all the results from samples containing 'high' levels of $B$ and subtracting the sums of the nature of base from samples containing 'low' levels of B. i.e.

$1 / 4\left[\left(B_{H} D_{L} S_{L}+B_{H} D_{H} S_{L}+B_{H} D_{H} S_{H}+B_{H} D_{L} S_{H}\right)\right.$ $\left.\left(B_{L} D_{L} S_{L}+B_{L} D_{H} S_{L}+B_{L} D_{H} S_{H}+B_{L} D_{L} S_{H}\right)\right]$ (1)

The amount by which the result of this treatment departed from zero (irrespective of

\section{Release properties of suppositories}

whether positive or negative) was a quantitative measure of the effect of $B$ on disintegration time or dissolution times of the suppositories. Similar expressions were used for finding the effects of drug type and presence of surfactant. To determine whether there was any interaction between two variables, the $t_{50}$ or DT values of the combinations in which they appeared together at either 'low' or 'high' levels were summed up and the sum of other combinations subtracted from the value obtained. For example, for B and D (B-D):-

$1 / 4\left[\left({ }_{L} D_{L} S_{L}+B_{L} D_{L} S_{H}+B_{H} D_{H} S_{H}+B_{H} D_{H} S_{L}\right)\right.$

$\left.\left(B_{L} D_{H} S_{L}+B_{L} D_{H} S_{H}+B_{H} D_{L} S_{L}+B_{H} D_{L} S_{H}\right)\right]$

A result of zero indicates no interaction, but a significant departure from zero implied that the two variables were interacting with each other. Similar expressions were used for estimating the interactions between $B$ and $S$ (B-S), and between S and D(S-D).

\section{Statistical Analysis}

The statistical significance difference in the drug release rate from formulations containing surfactant and those without surfactant was carried with Student t-test using Microsoft Excel software. At 95\% confidence interval, 2 -tailed $p$ values less than or equal to 0.05 were considered significant.

\section{Results and Discussion}

The representative plot of the dissolution profiles of the chloroquine and aminophylline suppositories are given in Figure 1 and 2 . The incorporation of Tween 80 at a concentration of $0.5 \% \mathrm{w} / \mathrm{v}$ resulted in a significant increase $(p<0.05)$ in the drug release rate when compared with the control suppositories (without surfactant). Values of disintegration time (DT) and time for $50 \%$ drug release $\left(t_{50}\right)$ for chloroquine and aminophylline suppositories are presented in Table 1. These values were used to calculate the independent and interaction 


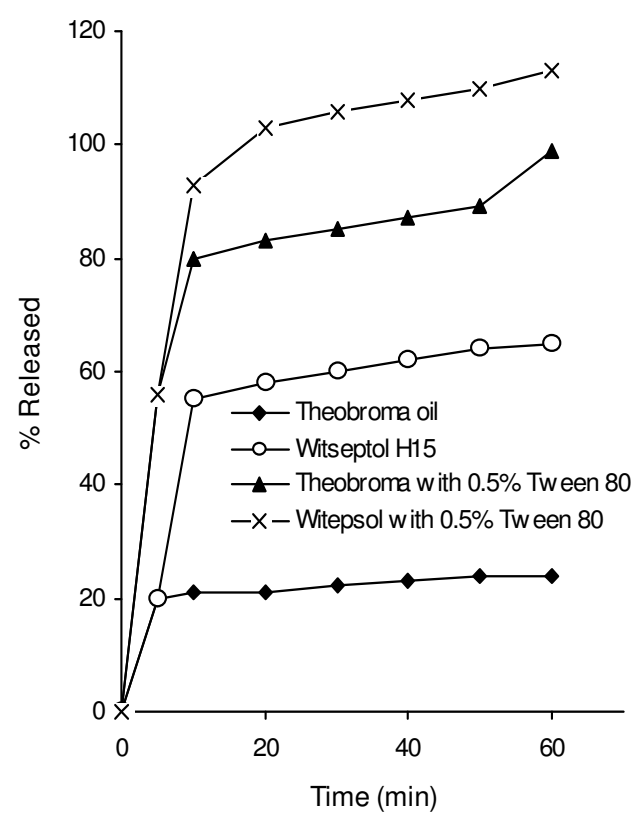

Figure 1: Dossolution profile of chloroquine phosphate suppositories formulated with theobroma oil and whitesop $\mathrm{H} 15$

coefficients for the variables using equations (1) and (2). The coefficient values are presented in Table 2. The individual and interaction effects provide a clear indication of the quantitative effects of the three variables studied on the disintegration times and $t_{50}$ of chloroquine and aminophylline suppositories.

In comparing the formulations, the ranking of the individual (independent) coefficient values (Table 2) for disintegration time DT, was $S>B>D$ and $S \gg>D>B$ for the dissolution parameter $t_{50}$. The presence of surfactant had the highest individual effect on both DT and $t_{50}$. This effect shows that the presence of a relatively small amount of surfactant $(0.5 \% \mathrm{w} / \mathrm{v})$ could lead to a significant change in disintegration and dissolution times. A similar effect was observed on Witepsol $\mathrm{H} 15$ base through the use of Cremophor $\mathrm{RH} \quad 60$ at $1 \% \mathrm{w} / \mathrm{v}$ concentration ${ }^{13}$.

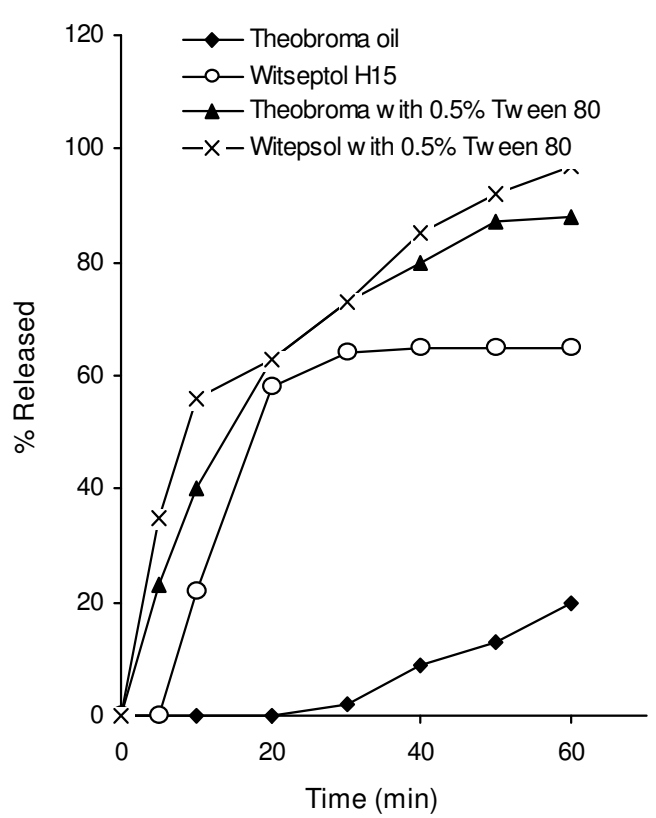

Figure 2: Dossolution profile of aminophylline suppositories formulated with theobroma oil and whitesop $\mathrm{H} 15$

The action of Tween 80 , which is non-ionic surfactant, is due to the increased water incursion into the oily bases by decreasing interfacial tension. Higher concentration of surfactants has been observed to decrease drug release due to formation of water in oil emulsion thereby entrapping the drug molecules ${ }^{14}$. Abd el-Gawad et al. ${ }^{14}$ also found that the technique of surfactant incorporation could have a great role in enhancing drug release from suppositories. The effect of $B$ on both parameters was negative although having a higher effect on disintegration time. Thus, changing the base from theobroma oil to Witepsol $\mathrm{H} 15$ led to a decrease in disintegration and dissolution times of the suppositories. This is probably due to the higher proportion of partial glycerides and hence higher hydroxyl value of Witepsol, making it more readily miscible with water than the more hydrophobic oil ${ }^{9}$.

Drug type had the lowest effect on disintegration time but a higher effect than 
Odeniyi \& Jaiyeoba, 2004

Table 1: Disintegration time (min) and time for $50 \%$ drug dissolution $t_{50}$ ( $\mathrm{min}$ ) for chloroquine and aminophylline suppositories for factorial experimental design

\begin{tabular}{lll}
\hline $\begin{array}{l}\text { Variables and } \\
\text { combination codes }\end{array}$ & DT (mins) & $\mathrm{t}_{50}$ (mins) \\
\hline $\mathrm{B}_{\llcorner} \mathrm{D}_{\mathrm{L}} \mathrm{S}_{\mathrm{L}}$ & 7.54 & 20.31 \\
$\mathrm{~B}_{\mathrm{L}} \mathrm{D}_{\mathrm{H}} \mathrm{S}_{\mathrm{L}}$ & 6.12 & 9.44 \\
$\mathrm{~B}_{\mathrm{L}} \mathrm{D}_{\mathrm{H}} \mathrm{S}_{\mathrm{H}}$ & 2.11 & 14.50 \\
$\mathrm{~B}_{\mathrm{L}} \mathrm{D}_{\mathrm{L}} \mathrm{S}_{\mathrm{H}}$ & 3.44 & 4.95 \\
$\mathrm{~B}_{\mathrm{H}} \mathrm{D}_{\llcorner} \mathrm{S}_{\mathrm{L}}$ & 6.14 & 13.16 \\
$\mathrm{~B}_{\mathrm{H}} \mathrm{D}_{\mathrm{H}} \mathrm{S}_{\mathrm{L}}$ & 6.25 & 19.25 \\
$\mathrm{~B}_{\mathrm{H}} \mathrm{D}_{\mathrm{H}} \mathrm{S}_{\mathrm{H}}$ & 1.45 & 5.03 \\
$\mathrm{~B}_{\mathrm{H}} \mathrm{D}_{\mathrm{L}} \mathrm{S}_{\mathrm{H}}$ & 1.02 & 8.25 \\
\hline
\end{tabular}

$\mathrm{B}_{\mathrm{L}}=$ nature of base (theobroma oil)

$\mathrm{B}_{\mathrm{H}}=$ nature of base (witepsol $\mathrm{H}-15$ )

$D_{L}=$ type of drug (chloroquine diphosphate)

$D_{H}=$ type of drug (aminophylline)

$\mathrm{S}_{\mathrm{L}}=$ absence of surfactant $(0 \%$ Tween 80$)$

$\mathrm{S}_{\mathrm{H}}=$ presence of surfactant $(0.5 \%$ Tween 80$)$

base type. Thus changing from chloroquine to aminophylline led to a decrease in disintegration time but increase in time for $50 \%$ of the drug to dissolve. This effect could be due to particle size and particle size distribution of the two drugs used in this study. This highlights the effect of drug type on the release profile of different bases and the need to select the best base for a particular drug in order to ensure optimum release. Akala et al. found that the best base to ensure optimum release for amodiaquine hydrochloride was polyethylene glycol ${ }^{8}$.

The interaction coefficients (Table 2) indicate the effects of the variables in combination. Ranking of the effects on disintegration time (DT) was $B-D>B-S>S-D$ and on $t_{50} S-D>B-$ $S>B-D$. The interaction effects between base and drug types had the highest effects on disintegration time and lowest effect on $t_{50}$. This effect gave a positive value indicating an increase in the time taken for disintegration and also for dissolution. However, B and S show a negative value of
Release properties of suppositories

Table 2: Quantitative effects of nature of base (B), type of drug (D) and concentration of surfactant (S) on disintegration time (DT) and $t_{50}$ and of suppositories

\begin{tabular}{lll}
\hline Variables & DT & \multicolumn{1}{c}{$\mathrm{t}_{50}$} \\
\hline \multicolumn{3}{c}{ Independent Coefficient } \\
B & -1.09 & \\
D & -0.55 & -0.88 \\
S & -4.51 & -7.55 \\
Interaction Coefficient & & \\
B - S & -0.45 & -2.21 \\
B - D & 0.82 & 1.05 \\
S - D & 0.10 & 2.78 \\
\hline
\end{tabular}

interaction implying a combination effect, which though less than the individual effect of the surfactant on the release, was a significant increase on the individual value of the base type effect. The magnitude of the interaction effects showed that there were generally considerable interactions between the presence of surfactant $S$ and the other two variables $D$ and $B$. This is probably due to the wetting effect of the surfactant leading to increased water incursion into the hydrophobic bases, dissolution of the drugs and consequent release of the water-soluble drugs.

\section{Conclusion}

There was considerable interaction between the variables for the different suppository formulations as shown by the magnitude of the individual and interaction coefficient obtained on the disintegration and dissolution times. The ranking of the effect of individual variables were found to be $S>>B>$ $D$ and $S>>>D>B$ for the dissolution parameter $t_{50}$, while the order of interactions found on disintegration time DT, was B-D>B$S>S-D$ and on $t_{50} S-D>B-S>B-D$. The results suggest that in formulating a water-soluble drug as a suppository in a hydrophobic base, the presence of surfactant is the most influential variable. 


\section{References}

1. Herman TW. Recent research on bioavailability of drugs from suppositories. Int. J. Pharm.1995;123:1-11.

2. Jaminet F. Aspects biopharmaceutiques de la formulacion des suppositoires. In: Guillot BR, Lombard AP (eds) Le Suppositoire.Maloine S.A., Paris.1973. pp 117-34.

3. de Boer AG, van Hoogdalem EJ, Breimer DD. Improvement of drug absorption through enhancers. Eur J. Drug Metab. Pharmacokine.1990; 15:155-7.

4. Ogosi T, Iwaki M, Tanino T, Fuji J, Paku T. Rectal absorption of acyclovir in rats and improvement of absorption by triglycerides. Biol. Pharm. Bull.1993; 16(3): 315-8.

5. Adeyemi MO, Pilpel N. The packing characteristics of physical and formulated mixtures of oxytetracycline and lactose powders. J Pharm Pharmacol. 1987 Sep;39(9):734-5

6. Zubair S. Esezobo S, Pilpel N. The Effects of interacting variables on the tensile strength, disintegration and dissolution of paracetamol tablets. J. Pharm. Pharmacol 1988; 40:278-81.

7. Odeku OA, Itiola OA. Effects of interacting variables on the tensile strength and the release properties of paracetamol tablets.Trop. J. Pharm. Res 2003; 2(1): 147-53.
8. Akala EO, Adedoyin A, Ogunbona FA. Suppository formulations of amodiaquine: In vitro release characteristics. Drug Dev. Ind. Pharm. 1991; 17:303-7.

9. Onyeji CO, Adebayo SA, Babalola CP. Effects of absorption enhancers in chloroquine suppository formulations: I In vitro release characteristics. Eur. J. Pharm. Sci 1999;9: 131-6.

10. United States Pharmacopoeia XX (1980). Mack Printing Co. Easton.Pa.

11. Woolfall RC. An approach to product formulation. Soap Perfum Cosmet 1964;37:965-70.

12. Berko S, Regdon G Jr, Ducza E, Falkay G, Eros I. In vitro and in vivo study in rats of rectal suppositories containing furosemide. Eur J. Pharm Biopharm 2002; 53:3:311-5.

13. Margarit MV, Rodriguez $\mathrm{Cl}$, Cerezo A. Rectal bioavailability of water-soluble drugs: sodium valproate. J. Pharm. Pharmacol.1991; 43:721-5.

14. Abd el-Gawad AH, el-Din EZ, Abd el-Alim HA. Effect of surfactant incorporation techniques on sulphamethoxazole suppository formulations Pharmazie. 1988;43(9):624-7. 